\title{
Evaluating the durability performance of wood-based panels by a non-destructive bending test
}

\author{
Yoichi Kojima $^{1} \cdot$ Akira Sakakibara $^{1} \cdot$ Hikaru Kobori $^{1} \cdot$ Shigehiko Suzuki $^{1}$
}

Received: 14 October 2015/Accepted: 4 February 2016/Published online: 29 February 2016

(C) The Japan Wood Research Society 2016

\begin{abstract}
We evaluated the durability of wood-based panels by comparing their dynamic modulus of elasticity (Ed) when subjected to repetitive humid and dry treatments. The panels experienced 1-year and 3-month outdoor exposure periods in Shizuoka City, Japan. As the temperature increased, decrements of Ed retention increased. For the same relative humidity, deterioration of the wood-based panels increased with increasing temperature. The highest modulus of rupture (MOR) retention for all the panels was for the $40{ }^{\circ} \mathrm{C}$ treatment. As temperature increased, MOR retention tended to decrease. At the $80{ }^{\circ} \mathrm{C}$ treatment, MOR retention for particle board (PB) was less than $10 \%$. Compared to plywood (PW), retention of mat-formed boards declined. One of reasons is due to the difference of bonding configuration. Bonding point of plywood is plain surface, however, that of mat formed board is small point. Thus, bonding points of board are easily collapsed by the ingress of water. Furthermore, mat-formed boards are likely to spring back by water because they are strongly compressed during hot pressing. Ed retention of all the panels decreased within 2 months. After 2 months, the Ed retention of two types of oriented strandboard (OSB) and PW did not decrease significantly. Ed retention of PB gradually decreased. The deterioration behaviour of the same sample during both humid and dry treatments and the outdoor exposure test could be tracked using the non-destructive bending test. Moreover, although the mechanism of deterioration differed between the humid and dry treatment and outdoor exposure test, Ed and MOR were strongly associated $\left(R^{2}=0.77\right)$. These results suggest that it is feasible to estimate MOR from Ed using the non-destructive test.
\end{abstract}

Yoichi Kojima

aykojim@ipc.shizuoka.ac.jp

1 Faculty of Agriculture, Shizuoka University, Shizuoka, Japan
Keywords Wood-based panels - Durability performance $\cdot$ Non-destructive test - Dynamic modulus of elasticity $\cdot$ Humid and dry treatment

\section{Introduction}

Mat-formed wood-based panels such as particleboard (PB), medium-density fibreboard (MDF), and oriented strandboard (OSB) are widely used for residential construction. Reductions in the domestic production of veneer-based panel products in Japan have resulted in the increased use of mat-formed panel products for structural purposes. For such uses, long-term durability is one of the panels' most important properties [1,2]. Veneer-based materials, such as plywood (PW), have superior properties compared to other wood-based panels and numerous studies have focussed on their durability [3-9]. In contrast, many studies have focussed on correlating deterioration of mat-formed panels, caused by outdoor exposure with accelerated aging [10,11] including the use of ASTM D1037 [12], APA D-1 and D-4 [13], and V313 treatments [14].

Outdoor exposure tests have many disadvantages including the time consumed and the difficulty in implementing them. In addition, results from outdoor exposure tests are confounded with the test location [15]. In contrast, short-term tests assess changes in mechanical properties after accelerated aging treatments, such as water immersion, boiling, steaming, freezing, or drying. The results of outdoor exposure tests are sometimes used as basic indicators when selecting among standardized test methods $[16,17]$. In Japan, to evaluate the durability of wood-based panels, outdoor exposure tests at eight sites using commercial wood-based panels have been conducted by the Research Working Group on Wood-based Panels of the 
Japan Research Society since 2004. In our previous reports, we discussed the results of 5-year exposure in Shizuoka City and standardized accelerated aging tests [18-20].

Considering actual usage, these standardized methods are usually more severe than service conditions. Thus, a milder aging test, that is more similar to actual usage, is needed to evaluate the durability under service conditions.

The outdoor exposure and accelerated aging tests were evaluated before and after the aging treatment. It is impossible to measure the same specimen both before and after treatment, so numerous specimens are required. Moreover, it is impossible to measure some properties during the testing process. For these reasons, we focussed on non-destructive testing.

Among the non-destructive tests of wood-based materials, the flexural vibration method has been widely implemented [21-24]. The durability performance of nondestructive tests has not been reported. Dynamic modulus of elasticity $(\mathrm{Ed})$ based on resonance frequency measured during a vibration test can be used to evaluate the bending performance of wood-based materials [25]. The advantages of non-destructive tests are that (1) the process of deterioration during the aging test can be evaluated continuously using only one sample and (2) they are easier to conduct than destructive tests.

In this report, we conducted an original accelerated aging test comprising repetitive humid and dry treatments that could be compared to the outdoor exposure test. Relatively short-term (1-year and 3-month) outdoor exposure tests were conducted at Shizuoka, Japan. Our objectives were to evaluate durability performance over these two time periods using continuous non-destructive testing and to discuss the relationship between non-destructive and destructive tests.

\section{Materials and methods}

\section{Sample panels}

The three groups of commercial wood-based panels, OSB, $\mathrm{PB}$ and PW, which are widely used for construction in
Japan were employed for this research (Table 1). There were two types of OSB, so we compared four types of panel overall. The OSB panels were made from various wood species. The OSB samples used for this study were obtained from North America [OSB (N)] and Europe [OSB (E)]. Particleboard was type $18 \mathrm{P}$ in the JIS standard. The parallel direction of each panel surface was defined by the surface strand alignment of OSB, the machine direction of $\mathrm{PB}$, and the surface veneer grain direction of $\mathrm{PW}$. We tested panel pieces that were $300 \mathrm{~mm}$ long in the parallel direction $\times 50 \mathrm{~mm}$ wide.

\section{Repetitive humid and dry treatments}

We applied repetitive humid and dry treatments, which are milder than the standardized accelerated aging process. One cycle consisted of $90 \%$ relative humidity (RH) for 5 days, followed by 2 days of low humidity. Three different temperatures $\left(40,60\right.$ and $\left.80^{\circ} \mathrm{C}\right)$ were imposed for both treatments and implemented at each cycle. The values of $\mathrm{RH}$ at low humidity were about $40 \% \quad\left(40{ }^{\circ} \mathrm{C}\right), 10 \% \quad\left(60{ }^{\circ} \mathrm{C}\right)$, and $1 \% \quad\left(80^{\circ} \mathrm{C}\right)$. Six samples were taken from each treatment and each panel. We conducted the non-destructive bending test, based on flexural vibrations, after the high humidity treatment, and calculated the Ed according to the flexural vibration method. Test panels were supported at points slightly offset from each end, and a microphone was placed above one end. The other end was tapped with a mallet as shown in Fig. 1. Ed was computed from the fundamental frequency obtained from the fast Fourier transform (FFT) analyser as follows:

$\operatorname{Ed}(\mathrm{GPa})=\frac{48 \pi^{2} L^{4} F^{2} \rho}{4.730^{4} T^{2}} \times 10^{-12}$,

where $L$ is the length of specimen $(\mathrm{mm}), F$ fundamental frequency $(\mathrm{Hz}), \rho$ density of specimen $\left(\mathrm{g} / \mathrm{cm}^{3}\right), T$ is the thickness of specimen (mm).

After 35 cycles, samples were reconditioned at $20^{\circ} \mathrm{C}$ and $65 \%$ RH over 2 weeks, and the non-destructive bending test was repeated. Finally, the static bending test was conducted in accordance with JIS A-5908 [26] to

Table 1 Specifications of the commercial panels

\begin{tabular}{llllll}
\hline Abbreviation & Panel type & Adhesive & Thickness $(\mathrm{mm})$ & Density $\left(\mathrm{g} / \mathrm{cm}^{3}\right)$ & Construction \\
\hline OSB (N) & OSB & MDI & 12.5 & 0.64 & Three layer cross oriented \\
OSB (E) & OSB & MDI & 11.6 & 0.62 & Three layer cross oriented \\
PB & Particleboard & PF & 12.4 & 0.78 & Three layer \\
PW & Plywood & PF & 12.4 & 0.56 & Five-ply \\
\hline
\end{tabular}

$O S B$ oriented strandboard, $M D I$ methylene diphenyl diisocyanate, $P F$ phenol formaldehyde, $N$ North America, $E$ Europe 


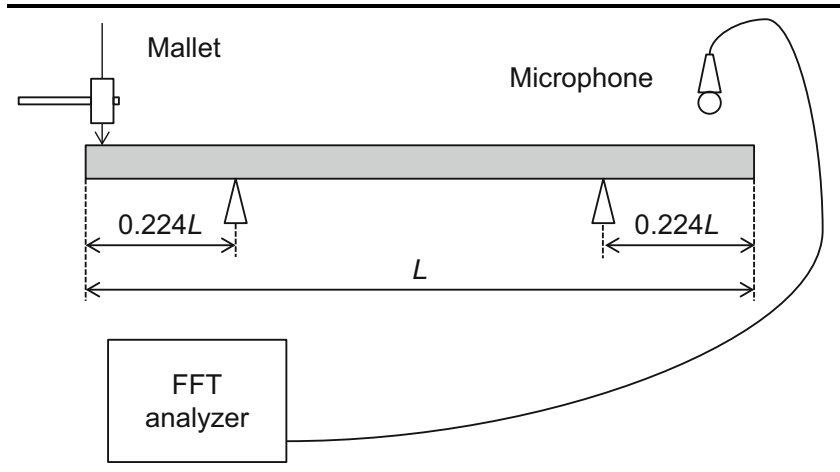

Fig. 1 Measurement of dynamic modulus of elasticity (Ed) using the FFT analyser

obtain the modulus of rupture (MOR) and modulus of elasticity (MOE).

\section{Outdoor exposure test in Shizuoka City}

We conducted an outdoor exposure test at Shizuoka University (Shizuoka City, Japan; $34^{\circ} \mathrm{N}, 138^{\circ} \mathrm{E}, 48 \mathrm{~m}$ above sea level). All panel samples (size $50 \mathrm{~mm} \times 300 \mathrm{~mm}$ ) were coated with a waterproof agent along their exposed edges, and set vertically on a southfacing exposure stand. The five exposure periods were: (1) annual: June 2014-May 2015; (2) summer season: June 2014-August 2014; (3) autumn season: September 2014November 2014; (4) winter season: December 2014-February 2015; and (5) spring season: March 2015-May 2015. Climate data collected during the outdoor exposure test at Shizuoka City are summarized in Table 2. Five samples were taken for each condition and each panel type. For the 1-year exposure, non-destructive bending tests were conducted once a month to obtain Ed. For the 3-month exposures, no measurements were taken during the exposure period. After outdoor exposure, specimens were dried at $60{ }^{\circ} \mathrm{C}$ for $24 \mathrm{~h}$ and then reconditioned at $20{ }^{\circ} \mathrm{C}$ and $65 \% \mathrm{RH}$ for 2 weeks. After conditioning, the non-destructive bending test was repeated to obtain $\mathrm{Ed}$ values. Finally, the static bending test was conducted in accordance with JIS A-5908 [26] to obtain MOR and MOE.

\section{Results and discussion}

\section{Characteristics of Ed retention for repetitive humid and dry treatments}

We define Ed retention as follows:

Ed retention $(\%)=(\mathrm{Ed}$ after treatment $/$ Ed before treatment $)$

$$
\times 100 \text {. }
$$

Figure 2 shows the variation in Ed retention during the humid and dry treatments for each panel. The decrease of $\mathrm{Ed}$ retention for PB was the greatest among the panels. After the first cycle, the Ed retentions for PB were $74.2 \%$ $\left(40{ }^{\circ} \mathrm{C}\right), 72.8 \%\left(60{ }^{\circ} \mathrm{C}\right)$, and $64.7 \%\left(80^{\circ} \mathrm{C}\right)$. For all panel types, Ed retention decreased during the initial stage of all treatments. This is why we recorded Ed after one cycle under humid conditions, while recording the initial measurement under dry conditions. As the temperature increased, decrements of Ed retention for all panels increased. From these results, for the same RH, higher temperatures caused greater deterioration of the woodbased panels. As shown in Fig. 2, when the non-destructive bending test is used, the deterioration behaviour of the same sample during the aging test can be followed.

Bending retention according to the static bending test after treatments.

We defined the bending retentions as follows:

MOR retention $(\%)=($ MOR after treatment $/$

$$
\text { MOR for control samples }) \times 100,
$$

MOE retention $(\%)=($ MOE after treatment $/$

$$
\text { MOE for control samples) } \times 100 \text {. }
$$

Figures 3 and 4 show the bending retentions following the static bending test. If retentions exceeded $100 \%$, they were set as $100 \%$ retention. For OSB (E) and PB, the highest MOR retentions occurred at the $40{ }^{\circ} \mathrm{C}$ treatment. For OSB (N) and PW, MOR retentions were not significant difference between the 40 and $60{ }^{\circ} \mathrm{C}$ treatment. With higher temperature treatments, MOR tended to be lower except for PW. For the $80{ }^{\circ} \mathrm{C}$ treatment, the MOR retention

Table 2 Climate conditions during the outdoor exposure test for Shizuoka City

\begin{tabular}{llccc}
\hline Term & Period & Average temperature $\left({ }^{\circ} \mathrm{C}\right)$ & Total precipitation $(\mathrm{mm})$ & Sunlight hours $(\mathrm{h})$ \\
\hline Summer & June 2014-August 2014 & 25.5 & 410.5 & 514.7 \\
Autumn & September 2014-November 2014 & 16.3 & 835.0 & 498.6 \\
Winter & December 2014-February 2015 & 8.1 & 443.0 & 651.0 \\
Spring & March 2015-May 2015 & 18.5 & 619.5 & 540.0 \\
Annual & June 2014-May 2015 & 17.0 & 2308 & 2204.3 \\
\hline
\end{tabular}



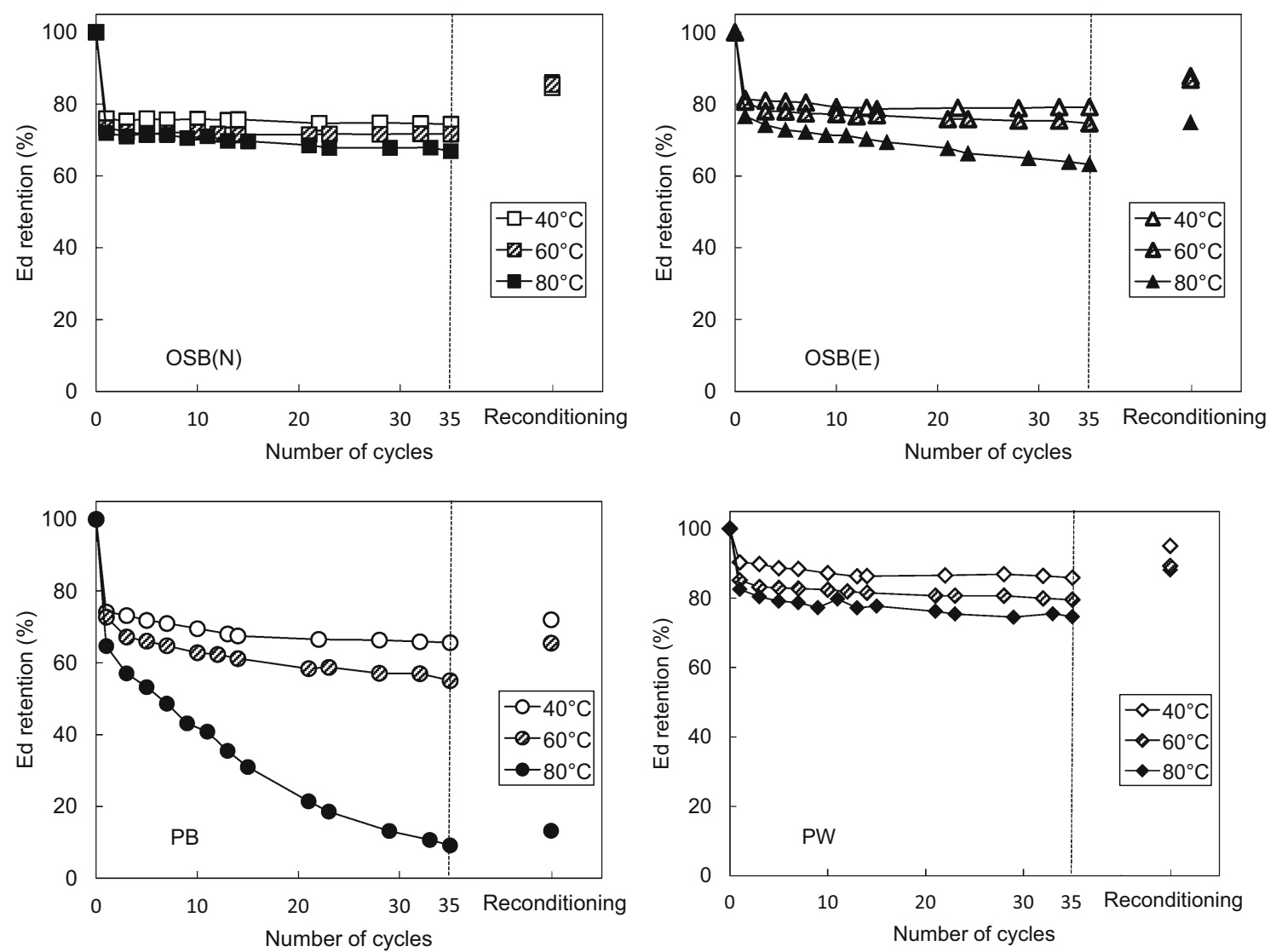

Fig. 2 The changes of dynamic modulus of elasticity (Ed) retention during humid and dry treatments for each panel. Reconditioning involved conditioning for 2 weeks at $20{ }^{\circ} \mathrm{C}$ and $65 \% \mathrm{RH}$. $O S B$ oriented strandboard, $P B$ particleboard, $P W$ plywood, $N$ North America, $E$ Europe

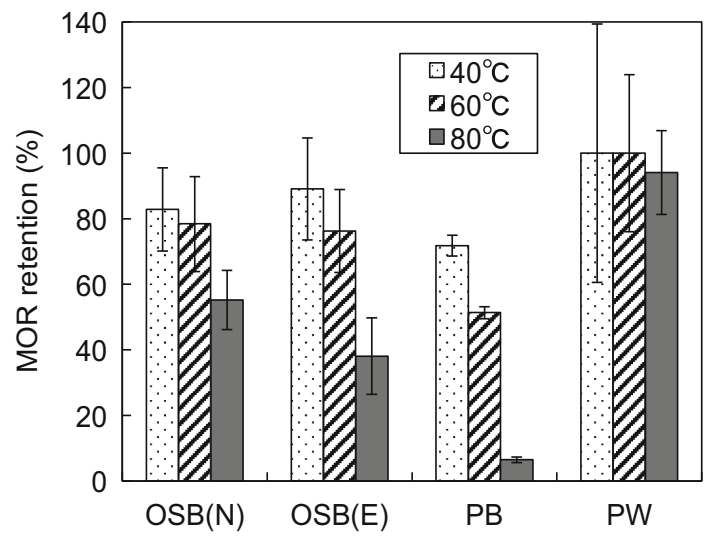

Fig. 3 Modulus of rupture (MOR) retentions after repetitive humid and dry treatments. $O S B$ oriented strandboard, $P B$ particleboard, $P W$ plywood, $N$ North America, $E$ Europe. Error bars represent standard deviations

for $\mathrm{PB}$ was $<10 \%$. The retentions of mat-formed boards were lower than those of PW. One of reasons is due to the difference of bonding configuration. Bonding point of plywood is plain surface, however, that of mat formed board is small point. Thus, bonding points of board are easily collapse by the ingress of water. Furthermore, mat-

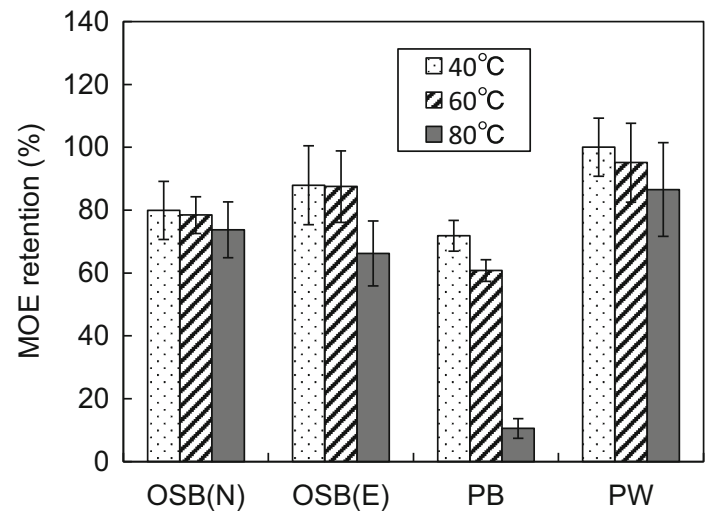

Fig. 4 Modulus of elasticity (MOE) retentions after repetitive humid and dry treatments. $O S B$ oriented strandboard, $P B$ particleboard, $P W$ plywood, $N$ North America, $E$ Europe. Error bars represent standard deviations

formed boards are likely to spring back by water because they are strongly compressed during hot pressing. The MOE retentions showed almost the same tendency as described for MOR retentions. Thus, at the same RH, higher temperatures resulted in greater deterioration of wood-based panels. 


\section{Outdoor exposure test in Shizuoka City}

The outdoor exposure test is a natural weathering method and provides the basis for applying laboratory-based accelerated aging test methods as practical standards. Figure 5 shows the change of Ed retention for the 1-year outdoor exposure test. Ed retention decreased within 2 months for all panels. After the 2-month period, Ed retention of the two types of OSB and PW did not drastically decrease. Ed retention of PB gradually decreased. For all panels, the Ed retentions increased in winter season. This is the reason that the humidity in winter season in Japan is usually lower than summer season, and the moisture content of specimen was lower in winter season than summer season. For PB, Ed retention of the repetitive humid and dry treatments at $40{ }^{\circ} \mathrm{C}$ was $72.0 \%$ after 35 repetitions. Ed retention after the 1-year outdoor exposure test was $46.6 \%$. From this result, it was found that the outdoor exposure test was more severe than the repetitive humid and dry treatment at $40{ }^{\circ} \mathrm{C}$. This is the reason that the deterioration from the outdoor exposure test might be caused by many factors, such as rainfall and ultraviolet rays. Rainwater causes deterioration due to alternating swelling and shrinking that deteriorates the bonding points in the panels.

Figures 6 and 7 show MOR and MOE retentions after outdoor exposure. For PB, bending retentions of annual exposure decreased more than those of seasonal exposure. For PW, there was not significant difference between annual exposure and seasonal exposure. The bending retentions of OSB (N) and $\mathrm{PB}$ were $<60 \%$ after 1-year exposure. In contrast, OSB (E) maintained high retentions over the same period. This explains the smoother surface of OSB (E) compared to OSB (N). Rainfall may have been

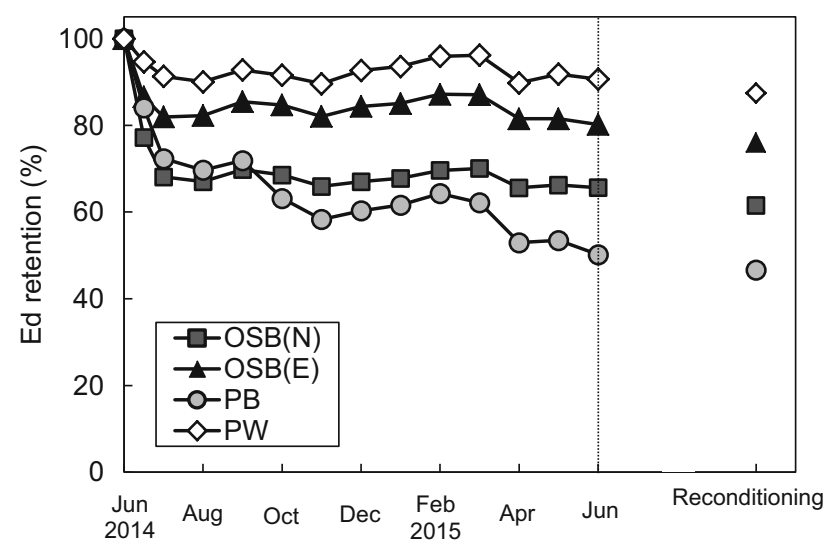

Fig. 5 The changes in modulus of elasticity (Ed) retention from the 1 -year outdoor exposure test in Shizuoka City. Reconditioning involved oven-drying for $24 \mathrm{~h}$ at $60{ }^{\circ} \mathrm{C}$, followed by 2 weeks of conditioning at $20^{\circ} \mathrm{C}$ and $65 \%$ RH. $O S B$ oriented strandboard, $P B$ particleboard, $P W$ plywood, $N$ North America, $E$ Europe

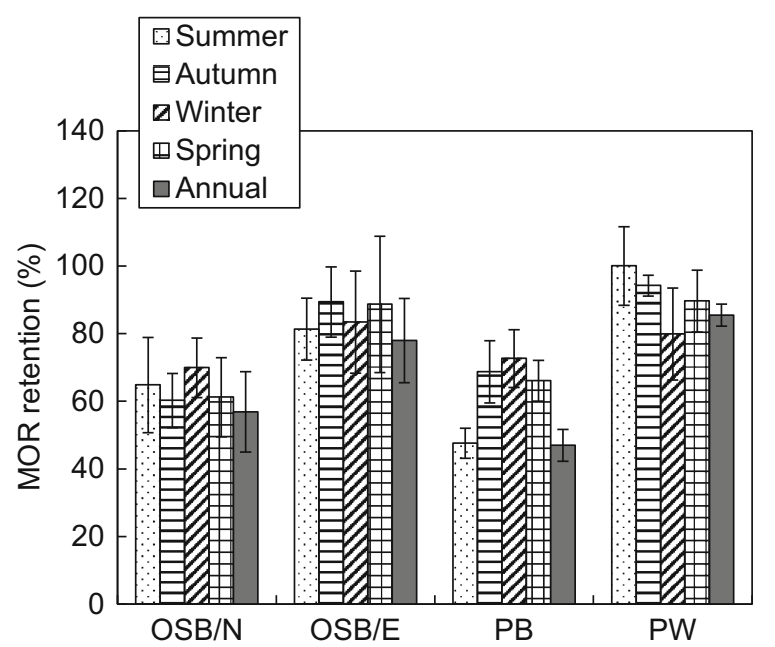

Fig. 6 Modulus of rupture (MOR) retentions after 4 types of outdoor exposure tests. $O S B$ oriented strandboard, $P B$ particleboard, $P W$ plywood, $N$ North America, $E$ Europe. Error bars represent standard deviations

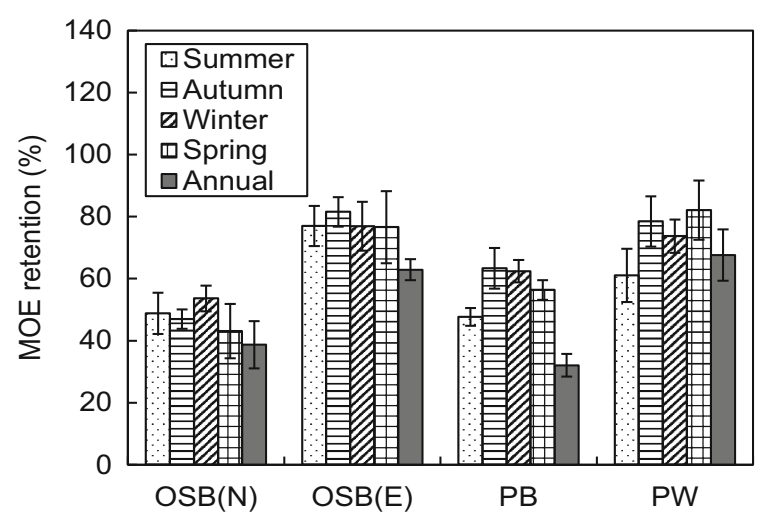

Fig. 7 Modulus of elasticity (MOE) retentions after 4 kinds of outdoor exposure test. $O S B$ oriented strandboard, $P B$ particleboard, $P W$ plywood, $N$ North America, $E$ Europe. Error bars represent standard deviations

retained by the rougher surface of OSB $(\mathrm{N})$. We suggest that the deterioration might be greater in response to higher temperature and greater precipitation.

\section{Relationships between Ed and MOR}

Figure 8 shows the relationship between Ed from the nondestructive test and MOR from the static bending test after reconditioning. This figure includes the results for two types of OSB and PB, including both humid-dry treatments and the five types of outdoor exposure treatments. The solid line represents the regression line. Despite the fact that mechanisms of deterioration were different for the humid and dry treatment and outdoor exposure test, the coefficient of determination for $\mathrm{Ed}$ and 


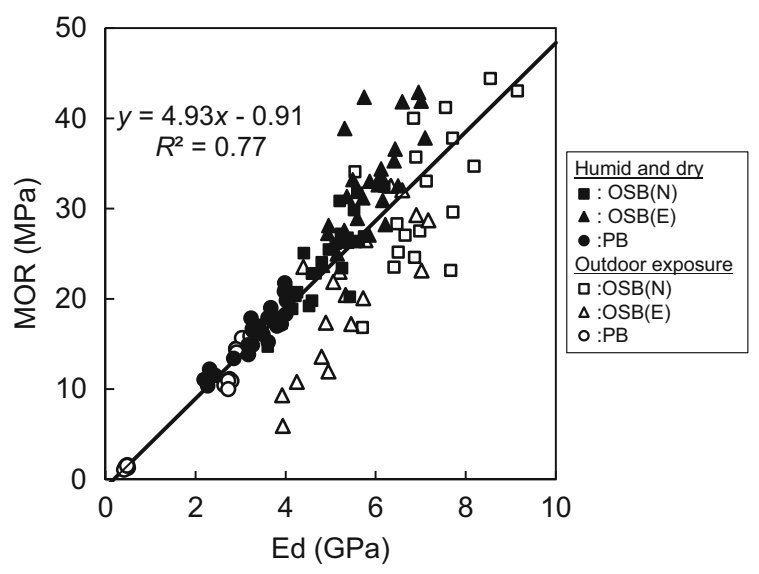

Fig. 8 Linear regression between Ed and MOR given by repetitive humid and dry treatments and 1-year and 3-month outdoor exposure tests. $O S B$ oriented strandboard, $P B$ particleboard, $N$ North America, $E$ Europe, $R^{2}$ the coefficient of determination

MOR was high $\left(R^{2}=0.77\right)$. These results indicate that it is feasible to estimate MOR from the Ed given by the non-destructive test without conducting destructive testing.

\section{Conclusions}

For residential construction, the durability is one of the most important properties for wood-based panels. We assessed the durability of four types of commercial woodbased panels under both humid and dry treatments using short- and long-term outdoor exposure tests at Shizuoka City. We tracked the deterioration of some samples during both tests using non-destructive methods. For humid and dry treatments, as the temperature increased, decrements of Ed retention increased. The highest $\mathrm{MOR}$ and $\mathrm{MOE}$ retentions were for the $40{ }^{\circ} \mathrm{C}$ treatment. Increased treatment temperature tended to result in lower MOR and MOE retentions.

The Shizuoka City 1-year outdoor exposure tests showed that Ed retention decreased within 2 months for all panels. After that, Ed retention of two types of OSB and PW did not drastically decrease. Ed retention of PB gradually decreased. The bending retentions of annual exposure decreased more than those of seasonal exposures, except for PW.

Despite the different mechanisms for the humid and dry treatments and the outdoor exposure test, the relationship of Ed and MOR was comparatively strong. These results indicate that it is feasible to estimate MOR based on Ed from non-destructive testing without conducting a destructive test to compute MOR directly.
Acknowledgments The authors acknowledge Asahikasei Homes Corporation for providing panels used in this study.

\section{References}

1. McNatt JD, Link CL (1989) Analysis of ASTM D1037 accelerated aging test. For Prod J 39:51-57

2. Kajita H, Mukudai J, Yano H (1991) Durability evaluation of particleboards by accelerated aging tests. Wood Sci Technol 25:239-249

3. Carroll MM, Bergin EG, Fiehl AO (1969) Accelerated and 5-year exposure tests on exterior type plywood. For Prod J 19:43-51

4. Black JM, Lutz JF, Mraz EA (1976) Performance of softwood plywood during 10 years' exposure to weather. For Prod J 26:24-27

5. Gillespie RH, River BH (1976) Durability of adhesives in plywood. For Prod J 26:21-25

6. Kaneda H (1977) Weatherability of plywood. I. Occurrence of surface checks and change of properties by exterior exposure (in Japanese). Wood Industry 32:387-391

7. Yoshida H, Taguchi $\mathrm{T}$ (1977) Bending properties of weathered plywood. I. Analysis of strength loss on exposed plywood (in Japanese). Mokuzai Gakkaishi 23:547-551

8. Inoue A (1992) A new method for predicting bond durability. I. Outdoor exposure test of plywood subjected to accelerated aging treatment (in Japanese). Mokuzai Gakkaishi 38:923-930

9. Biblis E (2000) Effect of weathering on surface quality and structural properties of six species of untreated commercial plywood siding after 6 years of exposure in Alabama. For Prod J $50: 47-50$

10. Lehmann WF (1977) Durability of composition board products. Proc WSU Symp Particleboard 11:351-368

11. Lehmann WF (1978) Cyclic moisture conditions and their effect on strength and stability of structural flakeboards. For Prod J 28:23-31

12. ASTM-D 1037 (1993) Standard test method for properties of wood-based fiber and particle panel materials. American Society for Testing and Materials (ASTM), West Conshohocken

13. APA PRP 108 (1994) Performance standards and qualification policy for structural-use panels. APA-The Engineering Wood Association, Tacoma

14. EN321 (1993) Fiberboards, cyclic tests in humid conditions. European Standard

15. Suzuki S, Watai J (2000) Literature review for durability performance of wood and wood-based material (in Japanese). Bull Shizuoka Univ For 24:63-70

16. Gressel P (1980) Testing and judging the durability of particleboard adhesives: a proposal for the establishment of generally valid testing guideline (in German). Holz Roh Werkst 38:17-35

17. Dinwoodie JM (1981) Characterizing the performance of chipboard in the United Kingdom. Proc WSU Symp Particleboard 15:59-78

18. Kojima Y, Norita H, Suzuki S (2009) Evaluating the durability of wood-based panels using thickness swelling results from accelerated aging treatments. For Prod J 59:35-41

19. Kojima H, Suzuki S (2011) Evaluating the durability of woodbased panels using internal bond strength results from accelerated aging treatments. J Wood Sci 57:7-13

20. Kojima H, Suzuki S (2011) Evaluation of wood-based panel durability using bending properties after accelerated aging treatments. J Wood Sci 57:126-133

21. Galginatis SV, Bell ER, Fine AM, Auer G, Roy J (1954) Nondestructive testing of wood laminates. Office of Naval Research, University of Louisville, Institute of Industrial Research 
22. Jayne BA (1959) Nondestructive test for wood laminates. Washington State Institute of Technology, bulletin no. 246. Washington State University, Division of Industrial Research

23. Jayne BA (1959) Vibrational properties of wood as indices of quality. For Prod J 9:413-416

24. Pellerin RF (1965) A vibrational approach to nondestructive testing of structural lumber. For Prod J 15:93-101
25. Miller DG (1963) Nondestructive testing of crossarms for strength. Canadian Department of Forest, publication no. 1021

26. JIS A-5908 (1994) JIS standard specification for particleboard. Japanese Standards Association, Tokyo 